\title{
Evolution of metabolic alterations 5 Years after early puberty in a cohort of girls predisposed to polycystic ovary syndrome
}

Soren Harnois-Leblanc ${ }^{1}$, Andréanne Trottier', Samuel Leblanc ${ }^{1}$, Marie-Claude Battista², David H. Geller ${ }^{3}$ and Jean-Patrice Baillargeon ${ }^{1,2^{*}}$ (D)

\begin{abstract}
Background: We and others have observed that young girls predisposed to polycystic ovary syndrome (PCOS) display defective insulin sensitivity, beta-cell function and non-esterified fatty acids (NEFA) suppressibility during early pubertal years, compared to controls. Our objective is to assess whether these differences in glucose and NEFA metabolisms persist after 5 years in late/post-puberty.

Methods: We conducted a prospective cohort study between 2007 and 2015 with 4-6 years of follow-up in an academic institution research center. We compared 8 daughters and sisters of PCOS women (PCOSr) to 8 agematched girls unrelated to PCOS ( \pm 1.5 years). Girls were assessed initially at 8-14 years old and re-assessed after a median follow-up of 5.4 years, at 13-21 years old. Our main measures were a frequently sampled intravenous glucose tolerance test (FSivGTT)-derived insulin sensitivity (IS) and beta-cell function (disposition index, Dl $\mathrm{FSivGTT}_{\text {); }}$ and indices of NEFA suppression during FSivGTT ( $\log _{n}$-linear slope of NEFA and $T_{50}$ Of NEFA suppression).

Results: At follow-up, both PCOSr and controls had similar results: IS $=3.2$ vs 3.4 ( $p=0.88$ ), $\mathrm{Dl}_{\text {FSivGT }}=1926$ vs 1380 $(p=0.44), \log _{n}$-linear slope $=-0.032$ vs $-0.032(p=0.88)$ and $T_{50} \mathrm{NEFA}=18.1 \mathrm{vs} 20.8 \mathrm{~min}(p=0.57)$. IS, Dl $\mathrm{I}_{\mathrm{FSivG}}$ and NEFA suppressibility were stable in PCOSr after 5 years, but decreased significantly in controls (all $p<0.05$ ).

Conclusions: Impaired metabolism observed during early puberty in girls predisposed to PCOS remains stable after 5 years whereas control girls deteriorated their metabolic parameters. Therefore, both groups become comparable in late/post-puberty. Early puberty may thus represent a window during which metabolic alterations are transiently apparent in girls at risk of PCOS.
\end{abstract}

Keywords: Polycystic ovary syndrome, Daughters, Puberty, Insulin sensitivity, Non-esterified fatty acids, Glucose homeostasis

\section{Background}

Polycystic ovary syndrome (PCOS) is a common disorder, affecting $6-12 \%$ of women of reproductive age $[1,2]$. It is defined as clinical and/or biochemical hyperandrogenism with ovarian dysfunction such as oligo-anovulation and/or polycystic ovaries, excluding any other androgen excess disorder [3]. Women suffering from PCOS will present

\footnotetext{
* Correspondence: JP.Baillargeon@USherbrooke.ca

${ }^{1}$ Division of Endocrinology, Department of Medicine, Faculty of Medicine and Health Sciences, Université de Sherbrooke, 3001, 12e Avenue Nord, Sherbrooke J1H 5N4, Québec, Canada

${ }^{2}$ Research Center, Centre Hospitalier Universitaire de Sherbrooke, 3001, 12e Avenue Nord, Sherbrooke J1H 5N4, Québec, Canada

Full list of author information is available at the end of the article
}

increased risk of cardiometabolic morbidities, with insulin resistance detected in 50 to $80 \%$ of the cases [4]. A greater prevalence of impaired glucose tolerance and type 2 diabetes is observed compared to women without PCOS for the same age and weight [5].

PCOS and its cardiometabolic features are more common in families. Twenty to $40 \%$ of daughters and sisters of women with PCOS will develop the syndrome [6]. Several studies have shown that first degree relatives of women with PCOS display higher visceral adiposity, insulin resistance and associated hyperinsulinemia [7-10], both in women and men. Daughters or sisters of women diagnosed with PCOS develop abnormalities in glucose metabolism 
during early pubertal years, before developing clinical features of the syndrome [11-15]. In fact, between 8 and 12 years of age, they display lower insulin sensitivity and beta-cell dysfunction when compared to age- and body mass index (BMI) -matched girls unrelated to PCOS [14, 15]. Our group also observed lower non-esterified fatty acid (NEFA) suppression in these girls predisposed to PCOS [15]. However, it is still unknown how these metabolic defects evolved during and after puberty in comparison to the normal physiological changes associated with puberty. It has indeed been shown that insulin sensitivity decreases significantly during puberty in girls [16].

Early appearance of metabolic disruptions before development of PCOS per se in predisposed girls suggests that emergence of PCOS could be influenced by metabolic factors that enhance ovarian hyperandrogenism, perhaps as a primary defect or perpetuating factor. Hyperinsulinemia is known to alter steroidogenesis in ovarian theca cell resulting in decreased levels of progesterone and increased testosterone [17]. Insulin will also reduce hepatic synthesis of sex-hormone binding globulin (SHBG) and subsequently raise circulating free testosterone levels [17]. Furthermore, altered NEFA suppression implies the resistance of adipocytes to insulin, which can enhance NEFA spillover to visceral organs. Muscle, liver and betacell dysfunction following overexposure to NEFA (lipotoxicity) has been observed in the development of insulin resistance and type 2 diabetes [18]. There is yet no evidence of a lipotoxic effect on androgen-secreting organs, but experimental overexposure to NEFAs has been shown to increase androgen levels in vivo [19] and in vitro [20]. These studies suggest that lipotoxicity could induce androgen overproduction in androgen-secreting glands.

Identification of early defects that precede PCOS development in predisposed girls is vital to our understanding of the pathogenesis of the syndrome, and to more accurately identify girls who could benefit from intensified follow-up and/or preventive interventions, such as lifestyle management. Keeping in mind this overarching objective, our first step was to assess how metabolic abnormalities evolved until late- and post-puberty in daughters or sisters of women with PCOS as compared to girls unrelated to PCOS. Accordingly, the specific aim of this controlled cohort study was to evaluate whether the metabolic abnormalities previously identified [15] during early puberty in daughters and sisters of women with PCOS persist 5 years later, in late puberty or early after puberty.

\section{Methods}

\section{Design}

We conducted a controlled cohort study at the research center of the Centre hospitalier universitaire de Sherbrooke (CHUS), an academic center.

\section{Study participants}

Participants were girls at risk of PCOS (PCOS relatives, $\mathrm{PCOSr}$ ) and control girls previously evaluated between 8 and 12 years old by our group [15]. Probands with PCOS were diagnosed and followed by Dr. Jean-Patrice Baillargeon at the Reproductive Endocrinology Clinic of the CHUS. Girls from the control group were recruited at the outpatient pediatric endocrine clinic, where they were followed for a stable condition, and were matched to PCOSr on the basis of age ( \pm 1.5 years).

Assignment of PCOS diagnosis in probands was based on the The Androgen Excess and PCOS Society criteria [3]: oligomenorrhea ( $\leq 8$ menstrual periods/year) or confirmed oligo-anovulation; clinical or biochemical signs of hyperandrogenism (acne, hirsutism, serum total testosterone $>2.7 \mathrm{nmol} / \mathrm{L}$ or calculated free testosterone $>25 \mathrm{pmol} /$ L) [21]; and exclusion of secondary causes, i.e. nonclassical congenital adrenal hyperplasia, abnormal thyroid function, hyperprolactinemia, evidence of androgensecreting tumours, Cushing's syndrome or acromegaly, or the use of medications known to affect levels of testosterone or 17OHPg within 3 months of testing.

PCOSr and controls girls of the original cohort were invited for follow-up 5 years after their initial research visit. Exclusion criteria from baseline were again verified: precocious puberty, medication known to affect glucose homeostasis such as insulin sensitizers, having diabetes or other uncontrolled metabolic disorder or following a highlyrestrictive diet or intense physical activity program. Contrarily to the baseline study, we allowed participants to use oral contraceptives because it was unethical to suspend their contraception method for few months.

\section{Clinical assessment of subjects}

Pubertal stages were determined according to Tanner criteria [22] and hirsutism according to the modified Ferriman-Gallway score [23]. The following anthropometric parameters were measured: weight, height, waist circumference, hip circumference, body fat mass and lean mass percentage using foot-to-foot bio-impedance (TANITA, Arlington Heights, IL, USA). BMI was calculated by dividing weight $(\mathrm{kg})$ by the squared height $\left(\mathrm{m}^{2}\right)$. BMI z-scores and percentiles were obtained from the Center for Disease Control and Prevention growth charts [24] (the maximum age of 19.99 years was used for participants $\geq 20$ years old). Obesity was defined as an age and sex adjusted BMI zscore $\geq 95$ th percentile [25]. Waist circumference was measured between the inferior costal margin and the iliac crest in standing position. Hip circumference was taken at the level of the femoral trochanters. Waist circumference (WC) is strongly associated with cardiometabolic risks [26] and can be adjusted for stature in child with the waist-to-height ratio (WHtR). WC and WHtR z-scores were obtained using LMS tables developed by Sharma et al. [27]. These indices 
of adiposity are more strongly associated with adverse metabolic outcomes than BMI [27].

\section{Experimental protocol}

Participants were assessed after a 12-h overnight fast for two research visits, same as the baseline study [15]. The 1st visit included anthropometric measures and physical examination described above, fasting blood sampling and a 2-h $75 \mathrm{~g}$ oral glucose tolerance test (OGTT). One month later, a $3 \frac{1}{2}$-hour insulin-modified, frequently sampled intravenous glucose tolerance test (FSivGTT) was performed (visit 2). In contrast to baseline visits, there was no measurement of sex hormones, considering the use of hormonal contraception in a large proportion of our study population at follow-up. Also, participants taking hormonal contraception were studied during the period without hormones in order to minimize their potential impact on metabolism.

\section{Oral glucose tolerance test (OGTT)}

Sampling for glucose, insulin and NEFA were collected at times $-15,-5,0,15,30,60,90$ and $120 \mathrm{~min}$ after glucose load (40 g/m $\mathrm{m}^{2}$ body surface area). Fasting values were the mean of times $-15,-5$ and 0 min. Areas under the curve (AUC) for glucose and insulin were calculated. Total adiponectin, leptin and triglycerides concentrations were assessed at time 0 and $120 \mathrm{~min}$. The following indices were calculated from the OGTT: Mastuda insulin sensivity index $\left(\mathbf{I S I}_{\text {Matsuda }}=10,000 /\right.$ [square root (fasting glucose $(\mathrm{mg} / \mathrm{dL}) \times$ fasting insulin $(\mu \mathrm{U} / \mathrm{mL})) \times($ AUC glucose $(\mathrm{mg} /$ $\mathrm{dL}) \times$ AUC insulin $(\mu \mathrm{U} / \mathrm{mL}))])[28,29]$, corrected insulin response to glucose at $30 \mathrm{~min}(\mathbf{C I R 3 0}=[$ insulin $30 \mathrm{~min}$ $(\mu \mathrm{U} / \mathrm{mL})] /[$ glucose $30 \mathrm{~min}(\mathrm{mg} / \mathrm{dL})-70])$ [30] and the corresponding disposition index $\left(\mathrm{DI}_{\mathrm{OGTT}}=\mathrm{ISI}_{\text {Mat- }}\right.$ suda $\times$ CIR30). The disposition index reflects insulin secretion adjusted for the level of insulin sensitivity and is therefore an estimation of beta-cell function [31].

After a glucose load, the insulin surge suppresses circulating NEFA levels. Indices of insulin-induced suppression of NEFA include the slope of the log-linear decrease of NEFA levels during the OGTT (Ln(NEFA) Slope) [32], and the T50 of NEFA suppression. T50 is defined as the time required for $50 \%$ suppression of NEFA levels at time 0 . We calculated the AUC of insulin during the same period using the trapezoidal method, which reflects total tissue exposure to insulin. Since NEFA suppression is regulated by circulating insulin levels, Ln(NEFA) Slope was corrected for insulin with the ratio $\mathbf{L n}(\mathbf{N E F A})$ Slope/ $\mathbf{A U C}_{\text {insulin }}$.

\section{Frequently sampled intravenous glucose tolerance test (FSivGTT)}

Fasting samples were taken at time $-15,-5$ and 0 min before the bolus of dextrose at time $0\left(11.4 \mathrm{~g} / \mathrm{m}^{2}\right.$ of body surface area). An intravenous bolus of $0.02 \mathrm{U} / \mathrm{kg}$ insulin
(Humulin Regular, Eli Lilly) was administered at time $20 \mathrm{~min}$ [28]. A total of 26 samples of glucose, insulin and NEFA were taken over $210 \mathrm{~min}$. Dynamic indices of glucose metabolism from glucose and insulin data were obtained using the minimal model of Bergman (MINMOD computer program version Millennium 6.02, Richard N. Bergman, 2004) [33]: insulin sensitivity (IS FSIVGTT) [28], insulin secretion (acute insulin response to glucose (AIRg)) [34] and the corresponding disposition index (DI $\mathbf{I}_{\mathbf{F}-}$ SIVGTT $=$ IS $_{\text {FSIVGTT }} \times$ AIRg) [35].

NEFA level suppression was estimated with the natural logarithm slope of NEFA levels (Ln(NEFA) Slope) during the endogenous insulin-induced NEFA suppression phase of FSivGTT (time 0 to $20 \mathrm{~min}$ ). We adjusted for area under the insulin curve calculated for the first $20 \mathrm{~min}$ of FSivGTT, using the ratio $\mathbf{L n}\left(\right.$ NEFA) Slope/AUC insulin. $_{\text {. }}$ The time for $50 \%$ suppression of NEFA levels ( $\mathbf{T} 5 \mathbf{0}_{\text {NEFA }}$ ) was assessed regardless of FSivGTT phases, but usually occurred during the first $20 \mathrm{~min}$ and thus reflected the effect of endogenous insulin [15].

\section{Assays}

Plasma glucose concentrations were assayed by the glucose hexokinase technique (Beckman Coulter, Brea, CA, USA). Human insulin was measured by an electrochemiluminescence immunoassay (ECLIA; Roche Diagnostics, Indianapolis, IN, USA). Leptin levels were measured by ELISA (Luminex Technology; EMD Millipore, Billerica, MA, USA). Total adiponectin levels were measured by radioimmunoassay (EMD Millipore, Billerica, MA, USA). NEFA and triglyceride concentrations were assayed using enzymatic colorimetric assays (Wako Chemicals, Richmond, VA, USA).

\section{Statistical analyses}

Results are expressed as medians with their interquartile range (25th and 75th). Groups were compared using Mann-Whitney tests. We used paired Wilcoxon tests to compare follow-up and baseline results. Since the change in WHtR z-score (from baseline to follow-up) was the adiposity measurement that was the most significantly different between groups, we adjusted group comparisons for changes in WHtR z-score using multiple linear regressions. Due to our small sample size, it was not possible to adjust for another factor. Statistical analyses were done

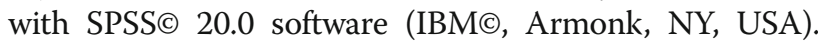
The level of significance was determined at $5 \%$.

\section{Results}

From the 9 girls having a first-degree relative diagnosed with PCOS and the 10 girls unrelated to PCOS recruited at baseline, we were able to reassess 7 girls from the PCOS relative group and 8 girls from the control group. Two PCOSr and one control girls withdrew between baseline and follow-up, 
and one control girl was lost to follow-up. A new PCOSr girl did a baseline visit just after the end of the baseline article [15] and had follow-up visit 5 years later. Hence, we report follow-up results for $8 \mathrm{PCOSr}$ and 8 control girls who we were able to match for age ( \pm 1.5 years).

As shown in Table 1, the median time to follow-up was 5.4 years for the entire group. Most girls were in their late or post-pubertal years (Tanner stage $\geq 4$ ) and postmenarchal. None of the girls presented hirsutism (Ferriman-Gallwey scores $=0$ ). Hormonal contraceptive use was the same in both groups (37.5\%). There were no differences in anthropometric measurements between groups at follow-up. Median BMI z-score was within normal range, but 2 girls in each group were obese ( $>95$ th percentile). Median WC and WHtR z-scores were between 15th and 35th percentiles, indicating normal degree of adiposity for age. One girl in the PCOSr group had WC and WHtR $\mathrm{z}$-scores over the 95th percentile, but none in the control group.

Table 2 shows fasting and $2 \mathrm{~h}$ results from the OGTT. Two-hour NEFA levels were significantly lower in PCOSr vs control girls $(p=0.003)$. Other markers were equivalent between PCOSr and control girls at follow-up. Fig. 1 presents similar curves of NEFAs levels across time for PCOSr and controls during OGTT and FSivGTT at follow-up.

Table 3 presents metabolic parameters derived from glucose, insulin and NEFAs measured during the OGTT and FSivGTT. Indices of insulin sensitivity and beta-cell function were similar between PCOSr and controls at follow-up. NEFA suppressibility during OGTT was higher in PCOSr vs control girls, as shown by a steeper $\log _{\mathrm{n}}$-linear slope of NEFA suppression, although this was no longer true after correction for insulin levels $\left(\mathrm{AUC}_{\text {Insulin }}\right)$. Furthermore, the $\log _{\mathrm{n}}$-linear slope of NEFA during FSivGTT and the T50 NEFA from OGTT and FSivGTT were similar between PCOSr and controls.

Variations of selected anthropometric and metabolic parameters during follow-up are shown in Table 4 . Adiposity measures did not vary significantly between baseline and follow-up, for either PCOSr or controls, except the WHtR that decreased in PCOSr and increased in control girls with a near significant between-group difference. Insulin sensitivity and beta-cell function derived from the OGTT and FSivGTT decreased significantly in control girls (OGTT: $p=0.012$ and 0.017, FSivGTT: $p=0.012$ and 0.012 , respectively), but not in PCOSr girls. These changes were significantly different between groups. Moreover, changes in $\mathrm{DI}_{\mathrm{OGTT}}$, IS $\mathrm{S}_{\mathrm{FSivGTT}}$ and $\mathrm{DI}_{\mathrm{FSivGTT}}$ remained significantly different between groups after correction for changes in WHtR z-score $(p=0.024,0.030$ and 0.034, respectively). Both OGTT-derived NEFA suppressibility indices significantly decreased in control girls ( $\log _{\mathrm{n}}$-linear slope: $p=0.017$ and T50 $\left.0_{\mathrm{NEFA}}: p=0.028\right)$. The $\log _{\mathrm{n}}$-linear NEFA slope significantly improved in PCOSr girls $(p=0.028)$, such that the change in $\log _{\mathrm{n}}$-linear NEFA slope was significantly different between groups. FSivGTT-derived NEFA suppressibility decreased in controls according to a longer T50 NEFA $(p=0.025)$, but remained stable in PCOSr girls. These changes were not significantly different between groups.

Table 1 Clinical and anthropometric characteristics at 5-year follow-up in controls and PCOSr girls

\begin{tabular}{lll}
\hline & Controls $(n=8)$ & PCOSr $(n=8)$ \\
\hline Age (years) & $17.6(14.6-20.2)$ & $17.5(14.4-20.1)$ \\
Duration of follow-up (years) & $5.4(5.3-6.0)$ & $5.6(4.6-6.6)$ \\
Tanner stage $\geq 4(\mathrm{n}, \%)^{\mathrm{a}}$ & $8(100.0)$ & $7(87.5)$ \\
FG score $>8(\mathrm{n}, \%)$ & $0(0.0)$ & $0(0.0)$ \\
Post-menarche $(\mathrm{n}, \%)$ & $7(87.5)$ & $7(87.5)$ \\
Hormonal contraceptives $(\mathrm{n}, \%)$ & $3(37.5)$ & $3(37.5)$ \\
Weight $(\mathrm{kg})$ & $57.4(45.7-77.6)$ & $58.5(54.2-73.9)$ \\
BMl $\left(\mathrm{kg} / \mathrm{m}^{2}\right)$ & $22.4(19.1-27.8)$ & $22.7(21.5-30.8)$ \\
BMl Z-score & $0.26(-0.96-1.52)$ & $0.63(0.02-1.71)$ \\
Obese $(\mathrm{n}, \%)$ & $2(25)$ & $2(25)$ \\
Fat percentage $(\%)$ & $27.6(13.4-37.9)$ & $29.0(24.1-35.4)$ \\
Waist circumference Z-score & $-0.98(-1.50-0.50)$ & $-0.38(-1.25--0.38)$ \\
WHtR Z-score & $-0.88(-1.06-0.54)$ & $-0.41(-1.04-0.57)$ \\
\hline
\end{tabular}

Continuous values are expressed as median (25th-75th percentile) and compared with Mann-Whitney test

Categorical values are expressed as $\mathrm{n}(\%)$ and compared with Chi-Square or Fisher's exact test

$B M I$ Body mass index, WHtR Ratio of waist circumference $(\mathrm{cm})$ to height $(\mathrm{cm})$;

FG score Ferriman-Gallwey score

${ }^{a}$ Tanner stage according to the highest score of its three components: pubic hair, axillary hair and breast development

There were no significant differences between groups according to $p$ values $>0.05$ 
Table 2 Metabolic measures at 5-year follow-up, during fasting and 2-h OGT, after $75 \mathrm{~g}$ glucose overload

\begin{tabular}{|c|c|c|c|c|}
\hline & \multicolumn{2}{|l|}{ Controls $(n=8)$} & \multicolumn{2}{|l|}{$\operatorname{PCOSr}(n=8)$} \\
\hline & Fasting & $2 \mathrm{~h}$ & Fasting & $2 \mathrm{~h}$ \\
\hline Glucose $(\mathrm{mmol} / \mathrm{l})$ & $5.0(4.6-5.3)$ & $5.7(5.1-7.3)$ & $4.6(4.4-4.8)$ & $5.8(5.3-6.8)$ \\
\hline Insulin (pmol/l) & $70(38-109)$ & $290(114-506)$ & $65(32-75)$ & $361(239-643)$ \\
\hline $\operatorname{NEFA}(\mu \mathrm{Eq} / \mathrm{L})$ & $395(234-616)$ & $25(17-41)$ & $582(391-661)$ & $11(4-14)^{a}$ \\
\hline Triglycerides (mmol/l) & $1.2(0.7-1.6)$ & - & $0.7(0.6-0.9)$ & - \\
\hline Total adiponectin (mg/l) & $9.8(6.9-12.2)$ & $10.4(6.9-13.6)$ & $10.7(8.5-15.4)$ & $11.8(8.7-15.7)$ \\
\hline Leptin $(\mu \mathrm{g} / \mathrm{l})$ & $8.4(2.9-14.3)$ & $7.5(2.5-17.6)$ & $8.6(4.4-15.4)$ & $6.1(3.6-21.6)$ \\
\hline
\end{tabular}

Values are expressed as median (25th-75th percentiles) and compared between groups with Mann-Whitney test

${ }^{\mathrm{a}}$ Significant difference between groups, $p$ value $=0.003$

To convert values for glucose to $\mathrm{mg} / \mathrm{dL}$, multiply by 18 ; for insulin to $\mu \mathrm{U} / \mathrm{mL}$, multiply by 0.17 ; for triglycerides to $\mathrm{mg} / \mathrm{dL}$, multiply by 88.50 NEFA Non-esterified fatty acids

\section{Discussion}

This study is the first report on the evolution of metabolic characteristics over 5 pubertal years in PCOS first-degree relatives and control girls matched for age. Interestingly, we found that alterations in glucose metabolism and NEFA suppressibility observed in girls at risk of developing PCOS during early/mid puberty [15] remained essentially stable over 5 years, into late and post-puberty. On the other hand, control girls' insulin sensitivity, beta-cell function and NEFA suppressibility decreased significantly during the same period; such that theses parameters decreased significantly more in controls vs PCOSr girls,

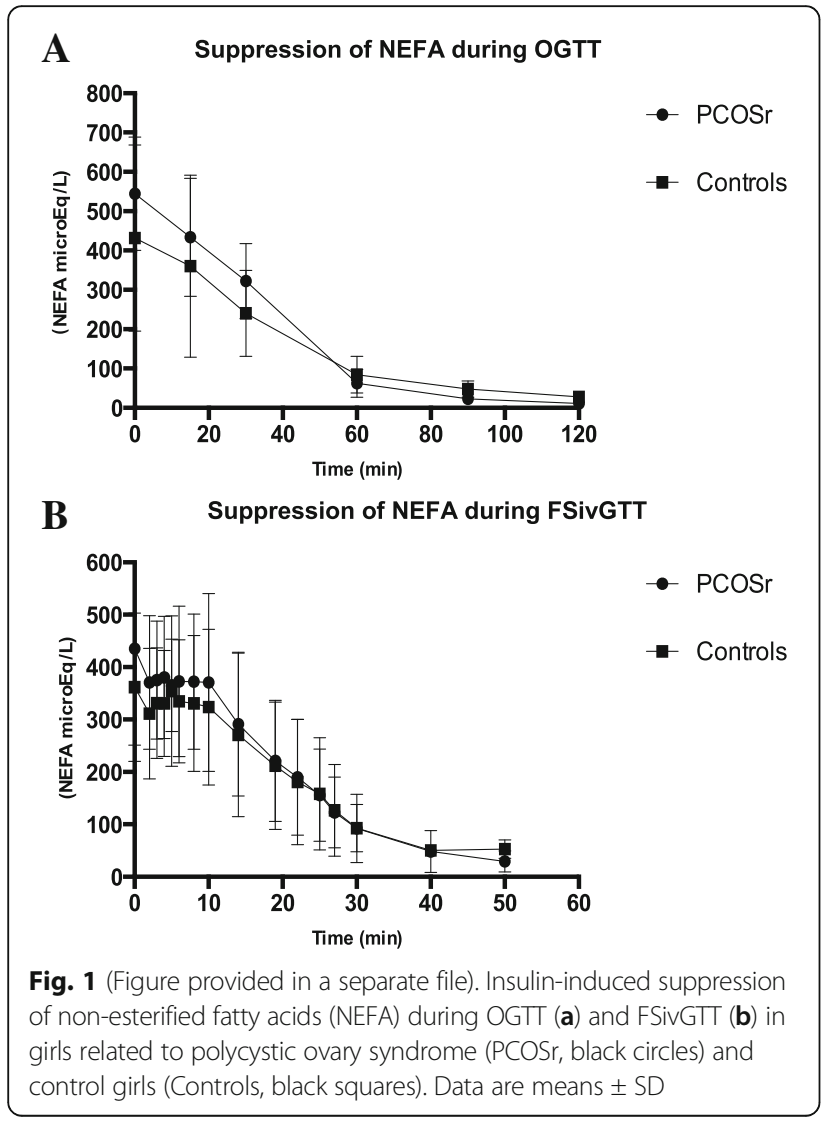

even after correction for changes in central adiposity (WHtR z-score). Accordingly, we observed that PCOSr and control girls display remarkably similar glucose homeostasis and NEFA suppressibility in late puberty or soon after puberty, in contrast with the significant impairment observed previously in PCOSr.

Other groups studying insulin dynamics in daughters or sisters of women diagnosed with PCOS during late pubertal stages of development relied primarily on the OGTT. A cross-sectional study [36] found that girls predisposed to PCOS $(n=92)$ displayed higher insulin levels $2 \mathrm{~h}$-post OGTT, at any Tanner stage, than controls matched for age and BMI $(n=76)$. Similar results were found in another study using salivary insulin levels $(n=17$ and 21 , respectively) [37]. Sir-Petermann et al. [11, 12] also observed higher $2 \mathrm{~h}$-insulin levels at any Tanner stage in PCOS first-degree relatives as compared to controls of the same BMI. On the other hand, Torchen et al. [14] observed similar insulin levels $2 \mathrm{~h}$ post-OGTT between PCOS first-degree relatives $(n=12)$ and controls $(n=10)$. In our study, 2-h insulin levels tended to be higher in PCOSr compared to control girls, but the ISI $_{\text {Matsuda }}$ was similar between groups. However, insulin levels during OGTT and ISI $_{\text {Matsuda }}$ are only estimations of insulin sensitivity, being less reliable than indices derived from the FSivGTT when compared to the gold standard hyperinsulinemic-euglycemic clamp in youth [28]. Furthermore, insulin clearance is reduced in PCOS women, compared to controls, which tends to increase insulinemia for the same degree of insulin sensitivity [38].

Consequently, we and others [14] have used FSivGTT to estimate systemic insulin sensitivity and beta-cell function in girls at risk of PCOS vs control girls. Torchen et al. [14] observed that beta-cell function remained lower over 2 years in PCOS at risk girls, from early to late pubertal stage (median Tanner stage of $\mathrm{V}$ at follow-up), compared to controls matched for age and BMI z-score. These results are similar to our baseline finding in this population [15]. On the other hand, insulin sensitivity was persistently similar between groups in Torchen's study, as opposed to 
Table 3 Calculated metabolic parameters at 5-year follow-up, based on OGTT and FSivGTT measures

\begin{tabular}{|c|c|c|c|c|c|}
\hline Conditions & Metabolic parameter & Calculated parameter & Controls $(n=8)$ & $\operatorname{PCOSr}(n=8)$ & $\mathrm{p}$ \\
\hline \multirow[t]{6}{*}{$\mathrm{OGT}$} & Insulin sensitivity & $|S|_{\text {Matsuda }}$ & $3.6(2.4-7.3)$ & $3.8(2.6-6.0)$ & 0.798 \\
\hline & Insulin secretion & CIR30 & $1.1(0.6-1.3)$ & $1.2(0.8-1.7)$ & 0.574 \\
\hline & $\beta$-cell function & $\mathrm{Dl}_{\mathrm{OGTT}}$ & $2.7(2.3-4.7)$ & $4.4(4.1-6.1)$ & 0.195 \\
\hline & \multirow[t]{3}{*}{ NEFA suppressibility } & $\log _{n}$-linear slope & $-0.028(-0.030--0.018)$ & $-0.040(-0.044--0.036)$ & $<0.001$ \\
\hline & & Log $_{n}$-linear slope / $A \cup C_{\text {insulin }}$ & $-0.58(-1.02--0.23)$ & $-0.81(-1.29--0.51)$ & 0.195 \\
\hline & & T50 $0_{\text {NEFA }}(\mathrm{min})$ & $40.6(28.3-48.5)$ & $34.1(24.4-47.0)$ & 0.645 \\
\hline \multirow[t]{6}{*}{ FSivGTT } & Insulin sensitivity & $\mathrm{IS}_{\mathrm{FSivGTT}}$ & $3.4(1.8-3.6)$ & $3.2(2.2-5.3)$ & 0.878 \\
\hline & Insulin secretion & AIRg & $790(343-813)$ & $496(361-997)$ & 0.959 \\
\hline & $\beta$-cell function & $\mathrm{Dl}_{\mathrm{FSivGTT}}$ & $1380(1122-2563)$ & 1926 (1376-2264) & 0.442 \\
\hline & \multirow[t]{3}{*}{ NEFA suppressibility } & $\log _{n}$-linear slope & $-0.032(-0.040--0.024)$ & $-0.032(-0.088--0.018)$ & 0.878 \\
\hline & & Log $_{n}$-linear slope / AUC insulin & $-4.33(-6.42--3.14)$ & $-3.33(-7.64--2.67)$ & 0.505 \\
\hline & & T50 NEFA $(\mathrm{min})$ & $20.8(16.2-26.9)$ & $18.1(16.1-23.9)$ & 0.574 \\
\hline
\end{tabular}

Values are expressed as median (25th-75th percentiles) and compared with Mann-Whitney test

AIRg Acute insulin response to glucose, AUC Area under the curve, CIR30 Corrected insulin response at 30 min, FSivGTT Frequent sampling intra-venous glucose tolerance test, DI Glucose disposition index, DI $I_{O G T} I S I_{\text {Matsuda }} \times C_{I R 30}, D I_{F S i v G T} I S_{F S i v G T T} \times A I R g, I S_{F S i v G T}$ Insulin sensitivity determined during the FSivGT, ISI Insulin sensitivity index, $\log _{n}$-linear slope Slope of Ln of NEFA concentrations (between time 0 to 20 min for the FSivGTT), Log ${ }_{n}$-linear slope /AUC Insulin Ratio of the Slope of Ln of NEFA concentrations to the area under the insulin curve $\times 1000$ (between time 0 to 20 min for the FSivGTT), NEFA Non-esterified fatty acid, OGTT Oral glucose tolerance test, and T50 NEFA Time to suppress $50 \%$ of NEFA baseline levels

our baseline results. This may be explained by the fact that our PCOSr girls had higher adiposity than controls at baseline. This suggests that during early puberty, girls at risk for PCOS are characterized by beta-cell dysfunction independent of adiposity, as shown in two different populations. Insulin sensitivity is more likely related to girls' adiposity.

We report the first cohort study on the evolution of glucose metabolism between early/mid puberty and late/post puberty in girls at risk for PCOS vs controls. Our study found significantly different changes in WHtR z-score between groups during this period $(p=0.05)$, explained by a decrease in PCOSr girls and an increase in controls. But even after correction for this change in WHtR z-score, we found that beta-cell function and insulin sensitivity deteriorated more in the control than the PCOSr groups. Consequently, glucose homeostasis of control girls matches PCOSr girls at the end of follow-up. Results of our control group may be explained by the normal transient insulin resistance observed during puberty. Using glucose-insulin

Table 4 Variations of selected metabolic parameters between follow-up and baseline and compared between PCOSr and controls girls

\begin{tabular}{|c|c|c|c|c|c|}
\hline Conditions & Metabolic parameter & Calculated parameter & Controls $(n=8)$ & $\operatorname{PCOSr}(n=8)$ & $p$ \\
\hline Duration of follow-up (years) & & & $5.4(5.3-6.0)$ & $5.6(4.6-6.6)$ & 1.000 \\
\hline \multirow[t]{2}{*}{ Anthropometric measures } & Adiposity & BMI Z-score & $0.81(-0.19-1.32)$ & $-0.08(-0.43-0.17)$ & 0.105 \\
\hline & & WHtR Z-score & $0.50(-0.18-1.07)$ & $-0.43(-0.93-0.21)$ & 0.050 \\
\hline \multirow[t]{4}{*}{ OGTT } & Insulin sensitivity & $|S|_{\text {Matsuda }}$ & $-7.7(-12.2--2.2)^{a}$ & $-0.7(-3.9-2.5)$ & 0.050 \\
\hline & $\beta$-cell function & $\mathrm{Dl}_{\mathrm{OGTT}}$ & $-4.0(-8.6--1.4)^{a}$ & $0.2(-1.6-3.4)$ & $0.010^{*}$ \\
\hline & NEFA suppressibility & $\log _{n}$-linear slope & $0.023(0.016-0.027)^{\mathrm{a}}$ & $-0.006(-0.014--0.001)^{\mathrm{a}}$ & 0.001 \\
\hline & & T50 NEFA $(\mathrm{min})$ & $18.2(3.4-33.5)^{\mathrm{a}}$ & $10.5(-0.6-17.4)$ & 0.161 \\
\hline \multirow[t]{5}{*}{ FSivGTT } & Insulin sensitivity & $\mathrm{IS}_{\mathrm{FSIVGTT}}$ & $-7.3(-11.6--4.6)^{\mathrm{a}}$ & $-0.5(-2.0-0.3)$ & $0.001^{*}$ \\
\hline & Insulin secretion & AlRg & $274(89-506)^{\mathrm{a}}$ & $190(56-328)^{a}$ & 0.442 \\
\hline & $\beta$-cell function & $D_{\text {FSivGTT }}$ & $-689(-1693--333)^{a}$ & $614(-151-1233)$ & $0.003^{*}$ \\
\hline & NEFA suppressibility & Log $_{n}$-linear slope & $0.015(0.003-0.033)$ & $-0.001(-0.067-0.012)$ & 0.083 \\
\hline & & T50 NEFA $(\mathrm{min})$ & $9.6(3.0-13.9)^{a}$ & $-1.3(-6.0-6.5)$ & 0.065 \\
\hline
\end{tabular}

Values are expressed as median (25th-75th percentiles) and compared with Mann-Whitney test

${ }^{a}$ Significant change between baseline and follow-up: $p<0.05$ analyzed with paired Wilcoxon test

${ }^{*} p<0.05$ after correction for the difference in WHtR Z-score between follow-up and baseline

AIRg Acute insulin response to glucose, FSivGTT Frequent sampling intra-venous glucose tolerance test, $D I$ Glucose disposition index, $D I_{O G T} I_{S I} I_{M a t s u d a} \times C I_{R 30}, D I_{F-}$ SivGT IS $\mathrm{I}_{\mathrm{FSivGT}} \times \mathrm{AIRg}, I \mathrm{~S}_{\mathrm{FSivG}}$ Insulin sensitivity determined during the FSivGT, ISI Insulin sensitivity index, Log $_{n}$-linear slope Slope of Ln of NEFA concentrations (between time 0 to $20 \mathrm{~min}$ for the FSivGTT), NEFA Non-esterified fatty acid, OGTT Oral glucose tolerance test, and T50 NEFA Time to suppress $50 \%$ of NEFA baseline levels and WHtR Ratio of waist circumference $(\mathrm{cm})$ to height $(\mathrm{cm})$ 
camp techniques, Hannon and colleagues [16] observed a $50 \%$ decrease of insulin sensitivity in girls with normal weight and Tanner stage of IV-V, in comparison to their pre-pubertal insulin levels independently of changes in adiposity. A decrease in our control group was therefore expected. For our PCOSr girls, it appears that defective beta-cell function and insulin sensitivity were already maximal at baseline, and thus could not deteriorate further. Interestingly, our results are supported by a recent study using a sheep model predisposed to PCOS [39]. Female offspring of prenatally testosterone-treated sheep displayed higher insulin-to-glucose ratio, an index of insulin resistance, as compared to control sheep before puberty, but no differences were observed between groups at post-puberty and early adulthood.

Our group uniquely measured NEFA suppressibility in girls at risk for PCOS, an assessment of insulin-mediated suppression of adipocyte lipolysis. This is important because defective NEFA suppression could lead to spillover of NEFA in non-adipose tissue, causing lipotoxicity [18]. Lipotoxicity is now established as a key factor in the development of insulin resistance and type 2 diabetes [18]. We previously published that PCOSr girls in their early-mid pubertal years were characterized by an important reduction in their insulin-mediated NEFA suppressibility compared to controls [15]. Now, we show that NEFA suppressibility did not significantly vary between early and late pubertal years in our PCOSr girls, in contrast to control girls, whose NEFA suppressibility indices decreased significantly. These results suggest that, similarly to glucose metabolism, the sensitivity of adipocytes to insulin-suppression of lipolysis decreases only in control girls during puberty, such that controls become similar to PCOSr girls by late or post-puberty. In addition to the impact of puberty, it could be argued that these results might be explained by the increase of central adiposity in control girls. However, no correlation between changes in WHtR z-score and NEFA indices was observed in our study.

The main pitfall of our study is the lack of power to detect small differences between groups, due to its small sample size. This concern is mitigated by the use of a robust and accurate method (FSivGTT). Significant results were obtained using robust statistical methods and are thus reliable. Although we assessed multiple parameters using two methods (OGTT and FSivGTT), our results are concordant within and between methods, which increases the validity of our results. Another limitation of our study is that $38 \%$ of girls in both groups were on hormonal contraception. Accordingly, we cannot report reliable results on sex hormone levels, clinical hyperandrogenism and oligoamenorrhea. Diagnosis of PCOS in at-risk girls was therefore impossible. Furthermore, only $40 \%$ of our PCOSrelated girls are expected to be diagnosed with PCOS at adulthood [6]. Hence, indicators of PCOS predisposition in our cohort could be diluted by the results of girls who will not develop PCOS. Nevertheless, important and significant metabolic alterations were found between PCOS at risk and control girls during early puberty by two different research team $[14,15]$, suggesting that our cohort of PCOSrelated girls remains an appropriate model to assess early predisposing factors to PCOS.

\section{Conclusions}

We found that early defects in both glucose and NEFA metabolism in girls genetically predisposed to PCOS remain stable throughout puberty, as compared with control girls whose metabolic parameters deteriorate significantly, such that both groups become similar by pubertal conclusion. Accordingly, the early pubertal period may represent a transient window of metabolic perturbations for girls predisposed to PCOS. This new knowledge suggests that efforts should be made to look for metabolic markers of PCOS development in girls at risk during the early pubertal phase, as opposed to late- or post-puberty. Since pubertal-associated insulin resistance resolves following puberty and PCOS adult women are more insulin resistant than control women, it is expected that glucose and NEFA metabolism in at-risk and controls will segregate again beyond young adulthood. A longer follow-up will be required to assess this evolution in girls predisposed to PCOS during adulthood. An ongoing multicenter prospective study with a larger cohort of girls having a firstdegree relative diagnosed with PCOS is led by Dr. David H. Geller (Los Angeles).

\section{Abbreviations}

AIRg: Acute insulin response to glucose; AUC: Area under the curve; BMI: Body mass index; CHUS: Centre hospitalier universitaire de sherbrooke; CIR30: Corrected insulin response to glucose at $30 \mathrm{~min}$; DI: Disposition index; FSivGTT: Frequently sampled intravenous glucose tolerance test; IS: Insulin sensitivity; ISI Matsuda: Matsuda insulin sensitivity index; Ln(NEFA) Slope: Slope of the log-linear decrease of non-esterified fatty acids levels; NEFA: Nonesterified fatty acids; OGTT: Oral glucose tolerance test; PCOS: Polycystic ovary syndrome; PCOSr: Daughters and sisters of women with polycystic ovary syndrome; T50 NEFA: Time required to suppress $50 \%$ of non-esterified fatty acids at time zero; WC: Waist circumference; WHtR: Waist-to-height ratio

\section{Acknowledgments}

The authors would like to sincerely thank Diane Lessard and Caroll-Lynn Thibodeau, research nurses who have organized the research visits, have monitored the OGTT and FSivGTT and have collected participant's medical and anthropometric parameters.

\section{Funding}

The study was partially founded by La Fondation des étoiles (Montréal, Québec) and self-supported by Dr. Baillargeon and Dr. Geller.

Availability of data and materials

The datasets used and/or analysed during the current study are available from the corresponding author on reasonable request.

\section{Authors contributions}

AT, MCB, DHG and JPB participated in study design and its execution. AT worked on data collection and SHL on data entry. SL did the laboratory analyses. SHL and JPB worked on data analyses and redaction of the 
manuscript. SHL, MCB, DHG and JPB participated in data interpretation. All authors reviewed and approved the manuscript.

\section{Ethics approval and consent to participate}

All participants and their parents (when participant was a minor) gave their informed written consent to participate to the five-year follow-up study. The human research ethical committee of the CHUS approved the present study.

\section{Consent for publication}

Not applicable.

\section{Competing interests}

The authors declare that they have no competing interests.

\section{Publisher's Note}

Springer Nature remains neutral with regard to jurisdictional claims in published maps and institutional affiliations.

\section{Author details \\ ${ }^{1}$ Division of Endocrinology, Department of Medicine, Faculty of Medicine and Health Sciences, Université de Sherbrooke, 3001, 12e Avenue Nord, Sherbrooke J1H 5N4, Québec, Canada. ${ }^{2}$ Research Center, Centre Hospitalier Universitaire de Sherbrooke, 3001, 12e Avenue Nord, Sherbrooke J1H 5N4, Québec, Canada. ${ }^{3}$ Department of Pediatrics, Cedars-Sinai Medical Center, 8700 Beverly Boulevard, Los Angeles 90048-1865, California, USA.}

\section{Received: 8 May 2017 Accepted: 14 July 2017}

\section{Published online: 24 July 2017}

\section{References}

1. Azziz R, Woods KS, Reyna R, Key TJ, Knochenhauer ES, Yildiz BO. The prevalence and features of the polycystic ovary syndrome in an unselected population. J Clin Endocrinol Metab. Endocrine Society. 2004 Jun;89(6):2745-9.

2. March WA, Moore VM, Willson KJ, Phillips DIW, Norman RJ, Davies MJ. The prevalence of polycystic ovary syndrome in a community sample assessed under contrasting diagnostic criteria. Hum Reprod. Oxford University Press. 2010 Feb;25(2):544-51.

3. Azziz R, Carmina E, Dewailly D, Diamanti-Kandarakis E, Escobar-Morreale $H_{\text {, }}$ Futterweit W, et al. The Androgen Excess and PCOS Society criteria for the polycystic ovary syndrome: the complete task force report. Fertil Steril. American Society for Reproductive Medicine. 2009 Feb 1;91(2):456-88.

4. Legro RS, Castracane VD, Kauffman RP. Detecting insulin resistance in polycystic ovary syndrome: purposes and pitfalls. Obstet Gynecol Surv. 2004 Feb;59(2):141-54.

5. Legro RS, Kunselman AR, Dodson WC, Dunaif A. Prevalence and predictors of risk for type 2 diabetes mellitus and impaired glucose tolerance in polycystic ovary syndrome: a prospective, controlled study in 254 affected women. J Clin Endocrinol Metab. Endocrine Society. 1999 Jan;84(1):165-9.

6. Kahsar-Miller MD, Nixon C, Boots LR, Go RC, Azziz R. Prevalence of polycystic ovary syndrome (PCOS) in first-degree relatives of patients with PCOS. Fertil Steril. 2001 Jan;75(1):53-8.

7. Yildiz BO, Yarali H, Oguz H, Bayraktar M. Glucose intolerance, insulin resistance, and Hyperandrogenemia in first degree relatives of women with polycystic ovary syndrome. J Clin Endocrinol Metab. 2003 May;88(5):2031-6.

8. Ünlühızarcı K, Özocak M, Tanrıverdi F, Atmaca H, Keleştimur F. Investigation of hypothalamo-pituitary-gonadal axis and glucose intolerance among the first-degree female relatives of women with polycystic ovary syndrome. Fertil Steril. 2007 Jun:87(6):1377-82.

9. Sir-Petermann T, Angel B, Maliqueo M, Carvajal F, Santos JL, Pérez-Bravo F. Prevalence of Type II diabetes mellitus and insulin resistance in parents of women with polycystic ovary syndrome. Diabetologia. Springer-Verlag. 2002 Jul:45(7):959-64.

10. Baillargeon JP, Carpentier AC. Brothers of women with polycystic ovary syndrome are characterised by impaired glucose tolerance, reduced insulin sensitivity and related metabolic defects. Diabetologia. 2007 Sep 27;50(12):2424-32.

11. Sir-Petermann T, Maliqueo M, Codner E, Echiburú B, Crisosto N, Pérez V, et al. Early metabolic derangements in daughters of women with polycystic ovary syndrome. J Clin Endocrinol Metab. 2007 Dec;92(12):4637-42.

12. Sir-Petermann T, Codner E, Pérez V, Echiburú B, Maliqueo M, Ladrón de Guevara A, et al. Metabolic and reproductive features before and during puberty in daughters of women with polycystic ovary syndrome. J Clin Endocrinol Metab. 2009 Jun;94(6):1923-30.

13. Raissouni N, Kolesnikov A, Purushothaman R, Sinha S, Bhandari S, Bhangoo A, et al. Altered glucose disposition and insulin sensitivity in peri-pubertal first-degree relatives of women with polycystic ovary syndrome. Int J Pediatr Endocrinol. BioMed Central Ltd. 2012;2012(1):14.

14. Torchen LC, Fogel NR, Brickman WJ, Paparodis R, Dunaif A. Persistent apparent pancreatic $\beta$-cell defects in Premenarchal PCOS relatives. J Clin Endocrinol Metab. 2014 Oct;99(10):3855-62.

15. Trottier A, Battista M-C, Geller DH, Moreau B, Carpentier AC, Simoneau-Roy J, et al. Adipose tissue insulin resistance in peripubertal girls with first-degree family history of polycystic ovary syndrome. Fertil Steril. Elsevier Inc. 2012 Dec 20;98(6):1627-34.

16. Hannon TS, Janosky J, Arslanian SA. Longitudinal study of physiologic insulin resistance and metabolic changes of puberty. Pediatr Res. 2006 Dec; 60(6):759-63.

17. Sharpe RM, Franks S. Environment, lifestyle and infertility-an intergenerational issue. Nat Cell Biol 2002 Oct;4 Suppl:s33-s40.

18. Carpentier AC. Postprandial fatty acid metabolism in the development of lipotoxicity and type 2 diabetes. Diabetes Metab. 2008 Apr;34(2):97-107.

19. Mai K, Bobbert T, Reinecke F, Andres J, Maser-Gluth C, Wudy SA, et al. Intravenous lipid and heparin infusion-induced elevation in free fatty acids and triglycerides modifies circulating androgen levels in women: a randomized, controlled trial. J Clin Endocrinol Metab. Endocrine Society. 2008 Oct;93(10):3900-6.

20. Bellanger S, Battista M-C, Fink GD, Baillargeon J-P. Saturated fatty acid exposure induces androgen overproduction in bovine adrenal cells. Steroids. 2012 Mar 10;77(4):347-53.

21. Pesant $\mathrm{M}-\mathrm{H}$, Desmarais $\mathrm{G}$, Fink GD, Baillargeon J-P. Reference ranges for total and calculated free and bioavailable testosterone in a young healthy women population with normal menstrual cycles or using oral contraception. Clin Biochem. 2012 Jan;45(1-2):148-50.

22. Marshall WA, Tanner JM. Variations in pattern of pubertal changes in girls. Arch Dis Child BMJ Group. 1969 Jun;44(235):291-303.

23. Ferriman D, Gallwey JD. Clinical assessment of body hair growth in women J Clin Endocrinol Metab. The Endocrine Society. 1961 Nov:21(11):1440-7.

24. Centers for Disease Control. Percentile Data Files with LMS Values [Internet]. 2009. Available from: https://www.cdc.gov/growthcharts/percentile_data_ files.htm.

25. Centers for Disease Control. Defining Childhood Obesity [Internet]. 2015. Available from: http://www.cdc.gov/obesity/childhood/defining.html

26. Després J-P, Lemieux I, Bergeron J, Pibarot $P$, Mathieu $P$, Larose $E$, et al. Abdominal obesity and the metabolic syndrome: contribution to global cardiometabolic risk. Arterioscler Thromb Vasc Biol. Lippincott Williams \& Wilkins. 2008 Jun;28(6):1039-49.

27. Sharma AK, Metzger DL, Daymont C, Hadjiyannakis S, Rodd CJ. LMS tables for waist-circumference and waist-height ratio Z-scores in children aged 519 y in NHANES III: association with cardio-metabolic risks. Pediatr Res. 2015 Sep 2;78(6):723-9.

28. Henderson M, Rabasa-Lhoret R, Bastard JP, Chiasson JL, Baillargeon JP, Hanley JA, et al. Measuring insulin sensitivity in youth: How do the different indices compare with the gold-standard method? Diab Metab. Elsevier Masson SAS. 2011 Feb 1:37(1):72-8.

29. Matsuda M, DeFronzo RA. Insulin sensitivity indices obtained from oral glucose tolerance testing: comparison with the euglycemic insulin clamp. Diabetes Care. 1999 Sep;22(9):1462-70.

30. Hanson RL, Pratley RE, Bogardus C, Narayan KM, Roumain JM, Imperatore $\mathrm{G}$, et al. Evaluation of simple indices of insulin sensitivity and insulin secretion for use in epidemiologic studies. Am J Epidemiol. 2000 Jan 15:151(2):190-8.

31. Buchanan TA, Xiang AH, Peters RK, Kjos SL, Berkowitz K, Marroquin A, et al. Response of pancreatic beta-cells to improved insulin sensitivity in women at high risk for type 2 diabetes. Diabetes. 2000 May;49(5):782-8

32. Carpentier A, Patterson BW, Leung N, Lewis GF. Sensitivity to acute insulinmediated suppression of plasma free fatty acids is not a determinant of fasting VLDL triglyceride secretion in healthy humans. Diabetes. 2002 Jun;51(6):1867-75.

33. Boston RC, Stefanovski D, Moate PJ, Sumner AE, Watanabe RM, Bergman RN. MINMOD Millennium: a computer program to calculate glucose effectiveness and insulin sensitivity from the frequently sampled intravenous glucose tolerance test. Diabetes Technol Ther. Mary Ann Liebert, Inc. 2003;5(6):1003-15. 
34. Marcelli-Tourvieille S, Hubert T, Pattou F, Vantyghem MC. Acute insulin response (AIR): review of protocols and clinical interest in islet transplantation. Diabetes Metab. 2006 Sep;32(4):295-303.

35. Kahn SE. The relative contributions of insulin resistance and beta-cell dysfunction to the pathophysiology of type 2 diabetes. Diabetologia. 2003 Jan;46(1):3-19.

36. Maliqueo M, Galgani JE, Pérez-Bravo F, Echiburú B, de Guevara AL, Crisosto $\mathrm{N}$, et al. Relationship of serum adipocyte-derived proteins with insulin sensitivity and reproductive features in pre-pubertal and pubertal daughters of polycystic ovary syndrome women. Eur J Obstet Gynecol Reprod Biol. 2012 Mar; 161(1):56-61.

37. Kent SC, Gnatuk CL, Kunselman AR, Demers LM, Lee PA, Legro RS. Hyperandrogenism and Hyperinsulinism in children of women with polycystic ovary syndrome: a controlled study. J Clin Endocrinol Metab. 2008 May:93(5):1662-9.

38. Amato MC, Vesco R, Vigneri E, Ciresi A, Giordano C. Hyperinsulinism and polycystic ovary syndrome (PCOS): role of insulin clearance. J Endocrinol Invest Springer International Publishing. 2015 Dec;38(12):1319-26.

39. Cardoso RC, Veiga-Lopez A, Moeller J, Beckett E, Pease A, Keller E, et al. Developmental programming: impact of gestational steroid and metabolic milieus on adiposity and insulin sensitivity in prenatal testosterone-treated female sheep. Endocrinology. 2016 Feb;157(2):522-35.

Submit your next manuscript to BioMed Central and we will help you at every step:

- We accept pre-submission inquiries

- Our selector tool helps you to find the most relevant journal

- We provide round the clock customer support

- Convenient online submission

- Thorough peer review

- Inclusion in PubMed and all major indexing services

- Maximum visibility for your research

Submit your manuscript at www.biomedcentral.com/submit
Biomed Central 